\title{
Do unliganded thyroid hormone receptors have physiological functions?
}

\author{
O Chassande \\ Biomatériaux et Réparation Tissulaire, INSERM U 577, Université de Bordeaux 2, Zone Nord, Batiment 4A, 2ème étage, 146 rue Léo Saignat, \\ 33076 Bordeaux, France \\ (Requests for offprints should be addressed to O Chassande; Email: Olivier.Chassande@bordeaux.inserm.fr)
}

\begin{abstract}
Thyroid hormone $(\mathrm{TH})$ is required for the development of vertebrates and exerts numerous homeostatic functions in adults. TH acts through nuclear receptors which control the transcription of target genes. Unliganded and liganded thyroid hormone receptors (TRs) have been shown to exert opposite effects on the transcription of target genes in vitro. However, the occurance of an aporeceptor activity in vivo and its potential physiological significance has not been clearly addressed. Several data generated using experimental hypothyroidism and thyrotoxicosis in wild type and TR knockout mice support the notion that apoTRs have an intrinsic activity in several tissues. ApoTRs, and in particular TR $\alpha 1$, are predominant during the early stages of vertebrate development and must be turned into holoTRs for post-natal development to proceed normally. However, the absence of striking alterations of embryonic and fetal development in mice devoid of TRs indicates that apoTRs do not play a fundamental role. During development, as well as in adults, apoTRs rather appears as a system which increases the range of transcriptional responses to moderate variations of T3.
\end{abstract}

Journal of Molecular Endocrinology (2003) 31, 9-20

\section{Introduction}

Thyroid hormone $(\mathrm{TH})$ has important roles in the metamorphosis of amphibians, in the postnatal development of birds and mammals, and in homeostasis of adults. The active form of $\mathrm{TH}$, tri-iodothyronine $\left(\mathrm{T}_{3}\right)$, controls the transcription of target genes in many tissues. Several genes have been shown to be activated by $\mathrm{T}_{3}$ [e.g. malic enzyme, $5^{\prime}$ deiodinase $(D I)$, myosin heavy chain $\alpha$ $(M H C a)$, the $\mathrm{K}^{+}$ionic channel gene $\left.(H C N 2)\right]$, but a large number of genes are repressed in response to this hormone [thyrotrophin releasing hormone $(T R H)$, thyroid stimulating hormone $\alpha$ and $\beta$ (TSHa and TSH $\beta$ ), myosin heavy chain $\beta(M H C \beta)$ ]. Indeed, in liver, the majority of $\mathrm{T}_{3}$-regulated genes are repressed in response to the hormone (Feng et al. 2000). $\mathrm{T}_{3}$-dependent gene transcriptional regulation is mediated by thyroid hormone nuclear receptors (TR), which are ligand-controlled transcription factors belonging to the superfamily of nuclear receptors. These receptors are encoded by two genes, TRa and TR $\beta$ (Yen 2001) that, in addition to the receptors, also generate proteins devoid of DNA binding or $\mathrm{T}_{3}$ binding, or both (Fig. 1, Table 1) (Chassande et al. 1997, 1999, Williams et al. 2000). The functions and mechanisms of action of these isoforms are largely unclear.

TRs associate with retinoid $\mathrm{X}$ receptors as heterodimers that bind to specific sites in the promoters of target genes (Glass 1994). They can adopt either the aporeceptor conformation (apoTR) when their ligand binding domain (LBD) is empty, or the holoreceptor conformation (holoTR) when the LBD is occupied by $\mathrm{T}_{3}$. In physiological situations, TRs are in equilibrium between the apoTR and holoTR conformations, depending on the local concentration of $\mathrm{T}_{3}$ and on 
$\mathrm{TR} \alpha$

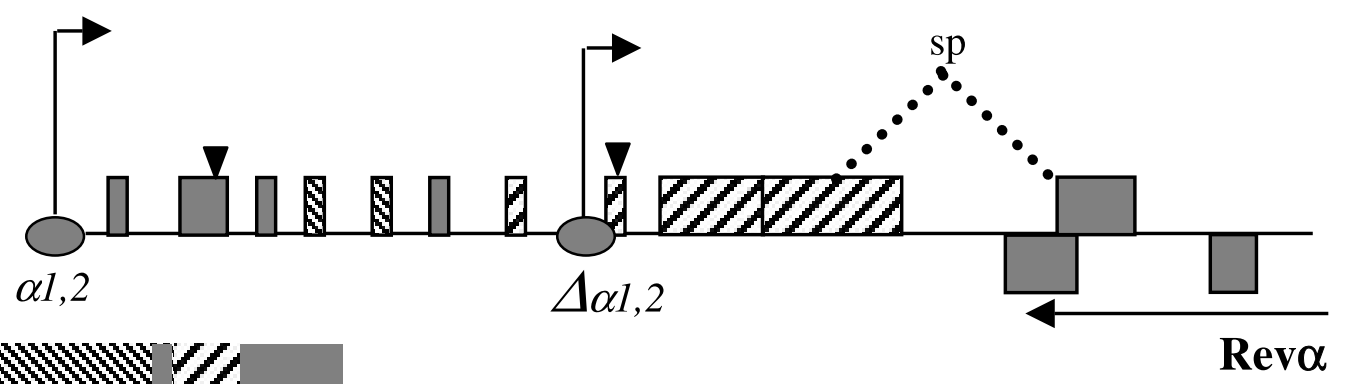

TR $\alpha 2$

TR $\alpha 1$

$\operatorname{TR} \Delta \alpha 1$

$\operatorname{TR} \Delta \alpha 2$

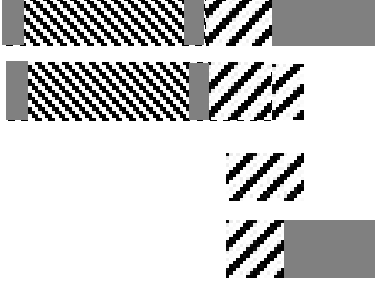

$\operatorname{TR} \beta$

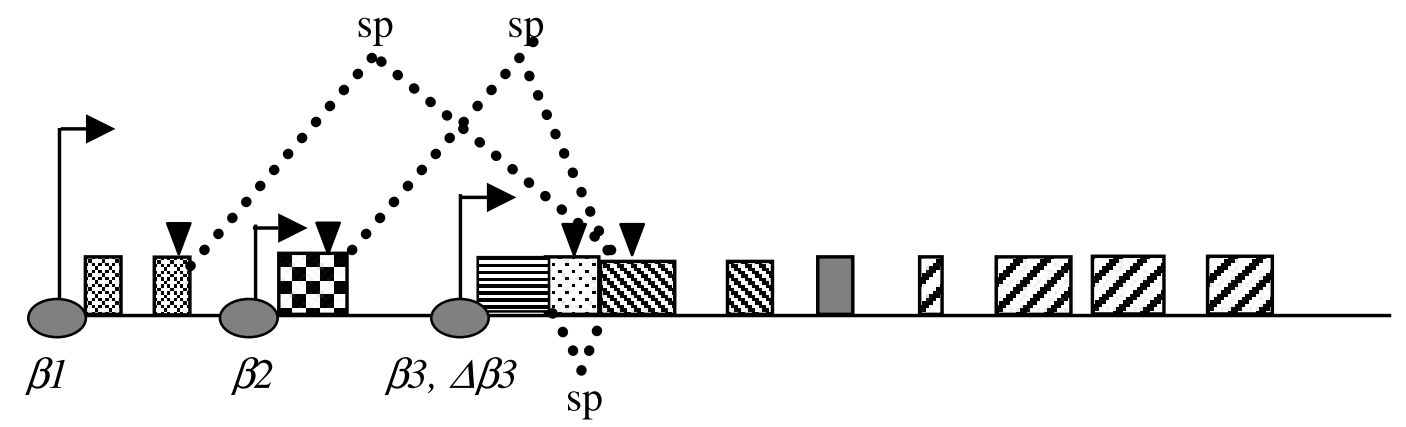

TR $\beta 1$

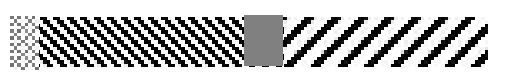

TR $\beta 2$

TR $\beta 3$

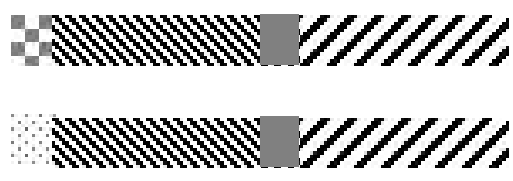

\section{TR $\Delta \beta 3$}

Figure 1 Structure of the TR $\alpha$ and TR loci and TR $\alpha$ and TR $\beta$ protein isoforms. Transcription initiation sites used to generate $\alpha 1+\alpha 2, \Delta \alpha 1+\Delta \alpha 2, \beta 1, \beta 2, \beta 3+\Delta \beta 3$ are represented by horizontal arrows anchored by vertical bars. Splice sites (sp) are represented by dashed lines. Translation AUG sites are represented by vertical arrows. DNA-binding domain (DBD)-encoding exons within the TR $\alpha$ and TRß genes and DBD domains within the TR proteins are represented as closely cross-hatched boxes. LBD-encoding exons within the TR $\alpha$ and TRB genes and LBD domains within the TR proteins are represented as widely cross-hatched boxes.

the affinity of $\mathrm{TR}_{\mathrm{s}}$ for $\mathrm{T}_{3}$. ApoTRs and holoTRs are themselves in rapid dynamic equilibrium between nucleoplasmic and DNA-bound forms. In addition, holoTRs are degraded by the proteasome pathway (Dace et al. 2000). As a consequence, a TH response element (TRE) within a $\mathrm{T}_{3}$ target gene may be either receptor-free or occupied by either the holoTR or the apoTR, the resulting effect on transcription depending on the concentration and proportion of holoTR and apoTR and on their respective intrinsic activities. Therefore, unlike membrane receptors or many nuclear receptors, 
Table 1 Functionality of the DNA-binding and ligand-binding domains within the TR isoforms and susceptibility of these isoforms to mutations. RTH-associated mutations were found in human and are inheritable. Somatic mutations were found in human tissues (Lin et al. 1999, MacCabe et al. 1999, Kamiya et al. 2002, Puzianowska-Kuznicka et al. 2002). Knock-in mutations mimick RTH-associated mutations and were introduced in the mouse TR $\alpha$ or TR $\beta$ genes

\begin{tabular}{|c|c|c|c|c|c|}
\hline & $\begin{array}{l}\text { DNA } \\
\text { binding }\end{array}$ & $\begin{array}{l}T_{3} \\
\text { binding }\end{array}$ & $\begin{array}{l}\text { RTH- } \\
\text { associated } \\
\text { mutations }\end{array}$ & $\begin{array}{l}\text { Somatic } \\
\text { point } \\
\text { mutations }\end{array}$ & $\begin{array}{l}\text { Knock-in } \\
\text { mutations }\end{array}$ \\
\hline TR $\alpha 1$ & + & + & & + & + \\
\hline TR $\alpha 2$ & + & - & & & \\
\hline TR $\Delta \alpha 1$ & - & - & & + & + \\
\hline TR $\Delta \alpha 2$ & - & - & & & \\
\hline TR $\beta 1$ & + & + & + & & + \\
\hline TR $\beta 2$ & + & + & + & & + \\
\hline TR $\beta 3$ & + & + & + & & + \\
\hline TR $\Delta \beta 3$ & - & + & + & & + \\
\hline
\end{tabular}

unliganded TRs are not silent, but compete for DNA binding with liganded receptors and exert a transcriptional activity that is the converse of that of holoreceptors. These properties confer on apoTRs a particular role in contributing to the transcriptional activity of $\mathrm{T}_{3}$ target genes, in combination with holoTRs: one considerable difference between a system in which aporeceptors are silent and a system in which aporeceptors have an antagonistic activity is that the latter offers a much greater amplitude of response to variations in ligand concentration (Fig. 2).

It has been demonstrated in vitro that, in the absence of $\mathrm{T}_{3}$, the LBD is tightly folded and binds corepressors, resulting in the repression of $\mathrm{T}_{3}$ activated genes by chromatin deacetylation. Upon $\mathrm{T}_{3}$ binding to the LBD pocket, the corepressor is released and the AF-2 domain becomes exposed and recruits coactivators, resulting in histone acetylation and chromatin loosening (Glass \& Rosenfeld 2000, Hu \& Lazar 2000). Despite abundant evidence for the role of corepressors and coactivators in TR activities in vitro, the mechanisms involved in $\mathrm{T}_{3}$-independent (apoTRmediated) and $\mathrm{T}_{3}$-dependent (holoTR-mediated) transcriptional control in vivo are not yet fully understood. To date, scarce evidence has been presented for the role of coactivators in holoTRmediated gene activation (Sadow et al. 2002). Transcriptional repression by holoTR does not seem to require the recruitment of corepressors (Becker et al. 2002), but rather that of coactivators (Weiss et al. 1999, 2002b), indicating that associ- ation with the coactivator is determined by the conformation of the receptor induced by $\mathrm{TR}-\mathrm{T}_{3}$ interaction, and is independent of the sense of the transcriptional effect. The in vivo involvement of corepressors in apoTR function is better established. NcoR has been found to be associated with apoTR in vivo (Sachs et al. 2002). Mutations of the TR $\beta$ gene resulting in delayed release of NcoR upon $\mathrm{T}_{3}$ binding have been found to be associated with the syndrome of resistance to thyroid hormone (RTH) (Liu et al. 1998, Safer et al. 1998, Tagami et al. 1998). Finally, when a dominant negative form of NcoR is expressed in the liver of transgenic mice, the expression of $\mathrm{T}_{3}$-activated genes is increased in the absence of $\mathrm{T}_{3}$, because of the loss of apoTR function (Feng et al. 2001). Together, these data strongly suggest that corepressors are associated with unliganded $\mathrm{TR}$ in vivo and that $\mathrm{T}_{3}$ binding causes the release of the corepressor. Therefore, as apoTR associates with corepressors, a potential role for apoTR could be to buffer corepressors. For instance, severe hypothyroidism, which generates increased amounts of apoTR, could result in the quenching of NcoR. This quenching could be responsible for the severe developmental abnormalities associated with severe hypothyroidism, reminiscent of the alterations caused by the absence of NcoR (Jepsen et al. 2000).

The question which is raised here is whether apoTRs have a physiological function. A prerequisite before analysing apoTR function is to identify when and where the unliganded TR is predominant. The literature provides data about the onset 
of thyroid function and of receptor expression, which makes it possible to draw up a pattern of evolution of the apoTR/holoTR ratio during fetal life. In adults, data from experimental hypothyroidism and thyrotoxicosis enable the determination of the apoTR/holoTR ratio in several tissues. Other important clues are revealed by analysing the consequences of forcing the TRs into the aporeceptor conformation, either by generating severe hypothyroidism or by introducing point mutations into the receptors that prevent $\mathrm{T}_{3}$ binding. These approaches will be used here to discuss the functions of unliganded TRs.

\section{The proportions of holoTR and apoTR are determined by central production of TH and deiodinase activities}

The proportion of apoTRs and holoTRs within a given cell depends on the local availability of $\mathrm{T}_{3}$. This availability depends on:

(i) central production of thyroxine $\left(\mathrm{T}_{4}\right)$ and $\mathrm{T}_{3}$

(ii) permeation of $\mathrm{T}_{4}$ and $\mathrm{T}_{3}$ through the cell membrane

(iii) local deiodination of $T_{4}$ to produce $T_{3}$

(iv) intracellular buffering systems

(v) mechanisms that control $\mathrm{T}_{3}$ shuttling between the cytoplasm and the nucleus, and

(vi) $\mathrm{T}_{3}$ catabolism by 5 deiodination.

Among all these parameters, central production and local metabolism of $\mathrm{T}_{4}$ and $\mathrm{T}_{3}$ by deiodinases are well documented, whereas the other steps of $\mathrm{TH}$ metabolism are poorly understood. Central production of $\mathrm{T}_{4}$ and $\mathrm{T}_{3}$ is controlled by the hypothalamic paraventricular nucleus thyrotrophin-releasing hormone (TRH) and pituitary thyroid-stimulating hormone (TSH). The local availability of $\mathrm{T}_{3}$ is mainly determined by the local production of $\mathrm{T}_{3}$ from its precursor $\mathrm{T}_{4}$ via $5^{\prime}$ deiodination and by inactivation of $\mathrm{T}_{3}$ through 5 deiodination (for review see Bianco et al. 2002). Type I deiodinase catalyses the $5^{\prime}$ deiodination of $\mathrm{T}_{4}$ and the 5 deiodination of $\mathrm{T}_{3}$; its expression is almost ubiquitous, but is not found in the central nervous system (CNS). Moreover, the expression of the type I deiodinase is low in the fetus. Type II deiodinase can catalyse the $5^{\prime}$ deiodination and is mostly abundant in the brain, but also in the

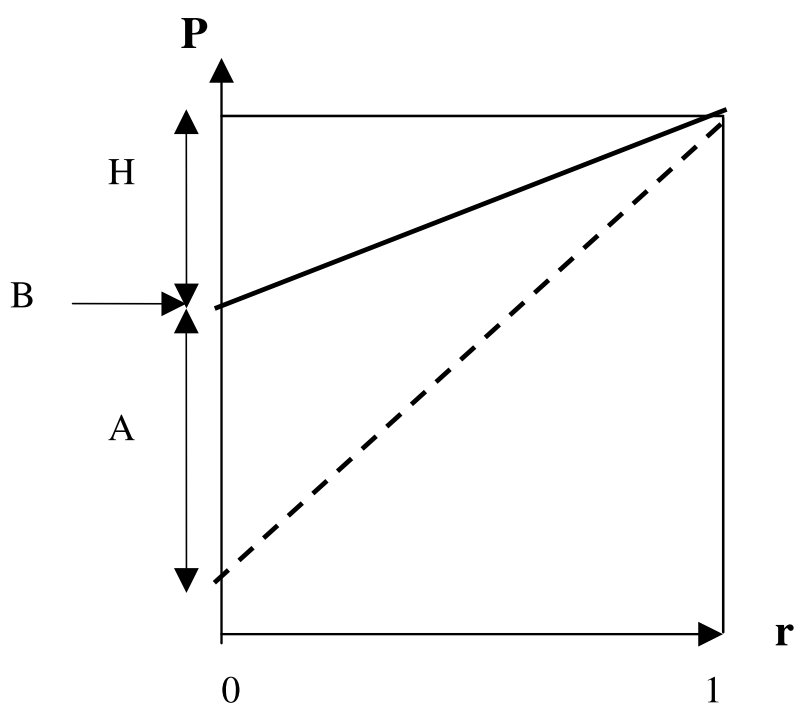

Figure 2 Activity of a $T_{3}$-dependent parameter as a function of holoR/TR ratio: effect of an intrinsic aporeceptor activity. The ordinate represents the activity $(P)$ of a $\mathrm{T}_{3}$-stimulated parameter (such as transcription, heart rate, etc.). The abscissa represents the holoTR/apoTR ratio $(r)$. The theoretical relationship between $P$ and $r$ obeys the equation: $P=B+(r \times H)+$ $(1-r) \times A$, where $B$ is the baseline activity in the absence of any regulation by TR (such as in TR-knockout mice), $A$ is the activity of apoTR and $H$ the activity of holoTR. With the hypothesis of a silent aporeceptor $(A=0)$, the theoretical curve is the continuous straight line. With the hypothesis of an intrinsic aporeceptor activity, the curve is the dashed line.

pituitary and in brown adipose tissue. Type III deiodinase catalyses the transformation of $\mathrm{T}_{3}$ into 3, $3^{\prime}$-di-iodothyronine and $\mathrm{T}_{4}$ into reverse $\mathrm{T}_{3}\left(\mathrm{rT}_{3}\right)$, which do not bind to TRs. It is particularly abundant in fetal tissues and through premetamorphosis in amphibians, thereby preventing premature exposure of the embryos or larvae to high concentrations of TH, which would result in developmental alterations. It is also present in many tissues in adults, in particular in regions of the CNS where TRs are abundant, such as the hippocampus, the dendate nucleus and the cerebral cortex. Production of type III deiodinase is stimulated by hyperthyroidism and inhibited by hypothyroidism. Local variations in $\mathrm{T}_{3}$ concentration can be determined by modifications in the activities of deiodinases, and both transcriptional and post-translational control of the expression of type I deiodinase can account for the variations in type I deiodinase activity. 


\section{Unliganded TRs are predominant at early stages of development}

In amphibians, avians, rodents and human, TRs are expressed before the onset of thyroid function. In amphibian larvae, onset of expression of TR $\alpha$ occurs at stage 39 and expression of TR $\beta$ at stage 46. $\mathrm{T}_{3}$ is detected from stage 56 only, suggesting that TRs work as aporeceptors until TH production is switched on (Damjanovski et al. 2002). The functionality of the $\mathrm{TR} \alpha$ receptors is demonstrated by the precocious induction of metamorphosis at stage 41 upon exogenous addition of $\mathrm{T}_{4}$ (Sachs et al. 2000). The function of apoTR could be important in premetamorphic amphibians, and it would be particularly interesting to analyse the effect of $T R$ gene inactivation in Xenopus to determine whether TRa has a function as a 'safety lock' to metamorphosis, in which case one would expect $T R a$ gene knockout to result in precocious metamorphosis.

In chicken embryo, the thyroid gland is functional at embryonic day 9.5 and $\mathrm{TH}$ concentrations increase until hatching. However, $\mathrm{T}_{3}$ and $\mathrm{T}_{4}$ are present at low concentrations in the egg yolk and $\mathrm{T}_{3}$ is released from the area opaca on the first day of development (E1) (Flamant \& Samarut 1998), suggesting that $\mathrm{T}_{3}$ might be available at the very beginning of chicken development. The TRa gene is detected from E1 and its expression is found in many tissues (brain, red blood cells, yolk sac) at E4, with a progressive increase until hatching (Forrest et al. 1990). The $T R \beta$ gene is detected as early as at E6-E7 in the yolk sack and in the retina (Forrest et al. 1990; Sjöberg et al. 1992). It is therefore likely that, between day 1 and day 10 , the receptors work mainly as aporeceptors, and are progressively turned into holoreceptors.

In mammals, the thyroid is fully functional at late stages of gestation (embryonic day 17 in rat, week 20 in human). Although THs are present early in the fetus, presumably through placental transfer from the mother, the combination of low amounts of type I deiodinase and large amounts of type III deiodinase in fetal tissues contributes to maintaining a low fetal concentration of $\mathrm{T}_{3}$ (Burrow et al. 1994). During this period, TRs are expressed in significant quantities. In rat brain for instance, $\mathrm{TR} \alpha 1$ is detected from embryonic day 11.5 in the neural tube, and its level increases progressively until day 19.5 (Bradley et al. 1992). From these data, we can extrapolate that, during the early fetal life, TRs are mainly present as apoTR, and are turned into holoR in postnatal animals, as TH concentrations increase. At least part of the TR must remain as aporeceptors to ensure a normal development, because thyrotoxicosis in fetus causes goitre, growth retardation, accelerated bone maturation, tachycardia and increased motility (Glinoer 2000). However, neither the inactivation of the $T R a$ or $T R \beta$ genes nor the inactivation of both genes has been reported to affect fetal development significantly, suggesting that apoTRs are not essential for the development of mammals. Instead, they should be considered as one component of a balanced system between apoTRs and holoTRs, which ensures optimized physiological functions.

\section{ApoTR must be turned into holoTR for postnatal development to proceed normally}

\section{Perinatal hypothyroidism locks receptors in their aporeceptor conformation and compromises development}

The perinatal period is characerized by a progressive increase in the serum concentration of $\mathrm{TH}$, which reaches a peak at birth in humans (Burrow et al. 1994) and at 15 days in mice (Hadj-Sahraoui et al. 2000). However, it is the local increase in $\mathrm{T}_{3}$ production that seems to account for the change in receptor occupancy within cells. A very nice description has been made of the role of type I deiodinase, $\mathrm{T}_{3}$ and $\mathrm{TRs}_{\mathrm{s}}$ in the onset of cochlear function during postnatal life. At 8 days after birth, there is a peak of type I deiodinase activity in the cochlea, associated with a peak in local $\mathrm{T}_{3}$ concentration (Campos-Barros et al. 2000), whereas serum $\mathrm{T}_{3}$ concentration remains low. This peak is correlated with the maturation of this organ, and the absence of TRs prevents its normal development (Rusch et al. 2001). As a consequence of increased $\mathrm{TH}$ concentration, during the perinatal period, a large proportion of the apoTR is turned into holoTR.

In some severe congenital or experimental $\mathrm{TH}$ deficiency states, the serum concentrations of $\mathrm{T}_{4}$ and $\mathrm{T}_{3}$ are dramatically reduced. Mice in which the Paxo gene has been inactivated are devoid of thyrocytes and hence cannot produce TH. These mice display very low concentrations of circulating 
$\mathrm{TH}$ at a time (15 days postpartum) when the serum concentration of $\mathrm{TH}$ normally reaches a peak in wild-type mice and allows for the postnatal maturation of many organs such as cochlea, intestine and brain. Consequently, $\mathrm{Pax}^{-{ }^{-}}{ }^{-}$mice display developmental arrest and die within the first 2 weeks of life (Mansouri et al. 1998). When $\mathrm{Pax}^{-}{ }^{--}$mice receive $\mathrm{T}_{4}$ transiently during the second week, they are rescued, recover normal growth and can survive for months as adults in the absence of any further administration of $\mathrm{T}_{4}$. Interestingly, the postnatal phenotype exhibited by deeply hypothyroid mice is qualitatively similar to that observed in mice lacking all TRs (slower growth, decreased mineralization of bones, smaller size of the spleen, impaired maturation of the intestine), but more severe (Flamant et al. 2002). In particular, TR double-knockout mice are viable, in contrast to $\mathrm{Pax}^{-1-}$ mice. The stronger phenotype exhibited by $\mathrm{Pax}^{-1-}$ mice as compared with TR double-knockout mice suggests two interpretations: (i) $\mathrm{T}_{3}$ acts via $\mathrm{TR} \alpha-$ and $\beta$-independent pathways and deprivation of $\mathrm{TH}$ affects functions other than those ensured by TRs; (ii) apoTRs exert a strong intrinsic activity that is extremely detrimental to postnatal development. This dilemma can be resolved by the following observations: (1) the very severe phenotype exhibited by $\mathrm{PaxO}^{-/-}$mice is partially rescued in combined Pax8- and TRa-knockout animals (Flamant et al. 2002) and (2) knockout of the TRa1 gene prevents alterations induced by hypothyroidism in the cerebellar structures of wild-type mice (Morte et al. 2002). In conclusion, the effects of the absence of $\mathrm{TH}$ can be attenuated by the removal of the TR $\alpha 1$ receptor, meaning that $\mathrm{TH}$ deprivation induces a strong apoTR $\alpha$ l activity in vivo that is extremely detrimental to postnatal development. Thus the role of $\mathrm{T}_{3}$ during the postnatal period in mammals might be to derepress the TR $\alpha 1$ receptor.

\section{Mutant receptors with impaired $\mathrm{T}_{3}$ binding preclude normal development}

Several naturally occurring or experimentally introduced mutations within the LBD of TRa1 or TR $\beta$ result in impaired $\mathrm{T}_{3}$ binding, providing conditions of in vivo apoTR. In humans, mutations within the TR $\beta$ LBD generate proteins with decreased affinity for $\mathrm{T}_{3}$, which compete with the wild-type receptors for binding to DNA targets and therefore act as dominant negative. Heterozygous patients display the family of syndromes collectively known as RTH (Refetoff 2001). The most common symptoms are increased $\mathrm{T}_{4}$ and $\mathrm{T}_{3}$ serum concentrations with normal or increased TSH, as the result of altered pituitary and hypothalamic feedback control of $\mathrm{TH}$ production. As a consequence of increased $\mathrm{TH}$ concentrations, TRa1 is mostly in the holoR conformation, resulting in a thyrotoxic phenotype in tissues in which this receptor is the major mediator of $T_{3}$ action; tachycardia is an example of such a phenotype. Mice harbouring mutations in the LBD of TR $\beta$ have been generated to provide experimental models to analyse the mechanisms of action of the dominant negative receptors, to provide better understanding of their tissue-specific effects and to offer the possibility of testing compounds aimed at restoring holoreceptor conformation of the mutant receptors and hence normal physiological activity. Mice with targeted mutations of the TR $\beta$ gene have impaired growth and RTH (Kaneshige et al. 2000), in addition to impaired development of the cerebellum (Hashimoto et al. 2001) associated with a learning defect. Interestingly, these phenotypes are not observed in mice with a homozygous deletion of the TR $\beta$ gene. The pattern of dominant negative TR $\beta$ activity is related to the proportion of $\mathrm{TR} \alpha$ and TR $\beta$ in each tissue (Zhang et al. 2002). For instance in liver, where the TR $\beta 1$ is the major TR isoform and where TR $\beta$ knock-in results in the abrogation of $\mathrm{T}_{3}$ binding, the activities of $\mathrm{T}_{3}$-activated genes are reduced in heterozygous or homozygous mutants, despite increased $\mathrm{TH}$ concentrations. In contrast, in heart where TR $\alpha 1$ is the major TR isoform, the $M H C a$ and $M H C \beta$ genes are up- and downregulated respectively, in response to increased concentrations of $\mathrm{TH}$.

The introduction of RTH syndrome mutations into the TRal gene results in a very severe hypothyroid phenotype reminiscent of that observed for the Pax8 ${ }^{-1}$ mice - characterized, for example, by severe retardation of postnatal development (Tinnikov et al. 2002) or mortality (Kaneshige et al. 2001). Tissues such as bone, heart and the immune system, in which deletion of the TR $\alpha 1$ receptor has been shown to produce alterations (Fraichard et al. 1997, Wilkstrom et al. 1998, Arpin et al. 2000, Gauthier et al. 2001), are severely affected by the TRa knock-in mutation. The predominant apoTR $\alpha 1$ is partly turned into 
holoTR $\alpha 1$ when excess $\mathrm{TH}$ is provided to the TRa knock-in heterozygous mice, resulting in phenotypic rescue. Worthy of note is that the phenotypes of TRa knock-in mice are much more severe than those of the TRa-knockout, TR $\beta$-knockout, TR double-knockout or TR $\beta$ knock-in mice. These observations further support the notion that a strong apoTR $\alpha 1$ activity has a toxic effect on postnatal growth and development. The expression of apoTR $\beta$ is clearly less detrimental to the overall development than is expression of apoTR $\alpha 1$; however, the contributions of the different aporeceptor and holoreceptor subtypes to normal development are difficult to analyse. In cerebellum, where TR $\alpha 1, \operatorname{TR} \alpha 2, \operatorname{TR} \beta 1$ and $\operatorname{TR} \beta 2$ have all been shown to be expressed (Strait et al. 1990; Bradley et al. 1992), the respective roles of $\operatorname{TR} \alpha 1$ and $\operatorname{TR} \beta$ aporeceptors are controversial. Hypothyroidism is known to affect cerebellar development and functions, and alterations in learning and movement have been reported in patients with the RTH syndrome. Remarkably, TR $\alpha$ - or TR $\beta$-knockout mice have not been reported to exhibit a significant cerebellum phenotype (Koibuchi \& Chin 2000; Flamant \& Samarut 2003). In contrast, the TR $\beta$ RTH mutation leads to altered maturation of the cerebellum and impaired learning, suggesting that postnatal occupancy of $\operatorname{TR} \beta$ receptors by $T_{3}$ is critical for the correct development of this organ (Hashimoto et al. 2001). In contrast with these findings, Morte et al. (2002) have shown that the deleterious effects of hypothyroidism on cerebellar development could be rescued either by the deletion of the TRa1 gene or by the administration of $\mathrm{T}_{3}$, but not by the injection of the $\mathrm{TR} \beta$ agonist GC-1, suggesting that it is the occupancy of the TR $\alpha 1$ receptor that is essential for the normal postnatal development of the cerebellum. Altogether, the above data suggest that maintaining either TR $\alpha 1$ or TR $\beta$ in the aporeceptor conformation is sufficient to block the maturation of the cerebellum or, put another way, all receptor subtypes must be derepressed by $\mathrm{T}_{3}$ to permit progression of the maturation.

In conclusion, it is remarkable that, in amphibians in addition to chicken and mammals, the $\mathrm{TR} \alpha \mathrm{l}$ receptor is found in the aporeceptor conformation during a long period corresponding to prenatal or premetamorphosis stages. If this receptor is maintained under this conformation during the perinatal period because $\mathrm{TH}$ concentrations remain low, or because it has a low affinity for $\mathrm{T}_{3}$, developmental processes are severely compromised. Moreover, even though persistence of apoTR $\alpha 1$ has the most deleterious effect, all receptors must be converted to the holoreceptor conformation during this period if normal development is to be ensured. However, the functions of apoTRs during the early stages of development remain unclear. The combined knockout of $T R$ genes has not revealed any obvious alteration in prenatal development, suggesting that apoTRs do not have an essential role. However, a more careful examination of the fetal phenotype of $T R$-knockout mice has yet to be carried out. Indirect evidence for a role of apoTR in fetal life is provided by the analysis of mice in which $\mathcal{N}_{c o} R$ has been deleted, resulting in altered apoTR activity. Erythrocyte precursors from $\mathcal{N}_{c o} R^{-1-}$ mice display increased expression of carbonic anhydrase II, a gene that is activated by $\mathrm{T}_{3}$ and is expected to be normally repressed by unliganded TR (Jepsen et al. 2000). Therefore the function of apoTR might be to block the transcription of $\mathrm{T}_{3}$ target genes at a fetal/larval level before the increase in $\mathrm{T}_{3}$ concentration, thereby maintaining a fetal/larval state in many tissues. It is likely however that, at least in mammals, redundant systems can substitute for TRs to exert this function.

\section{Role of apoTRs in adults}

Knock-in mouse models have not allowed for the analysis of apoTR function in adults, because all the phenotypes observed are developmental or could have a developmental cause. Most of the information about apoTR/holoTR ratios and aporeceptor function in adults has been provided by studies analysing the transcriptional effects of experimental hypothyroidism or thyrotoxicosis in adult tissues. This information allows for the determination of the percentage of receptor occupancy and, in combination with data from knockout mice, for the determination of the intrinsic apoTR activities in several tissues.

\section{Role of ApoTRs in adult liver, heart and pituitary}

Assuming that the transcriptional activity of a $\mathrm{T}_{3}$-regulated gene is a linear function of the 
(a)

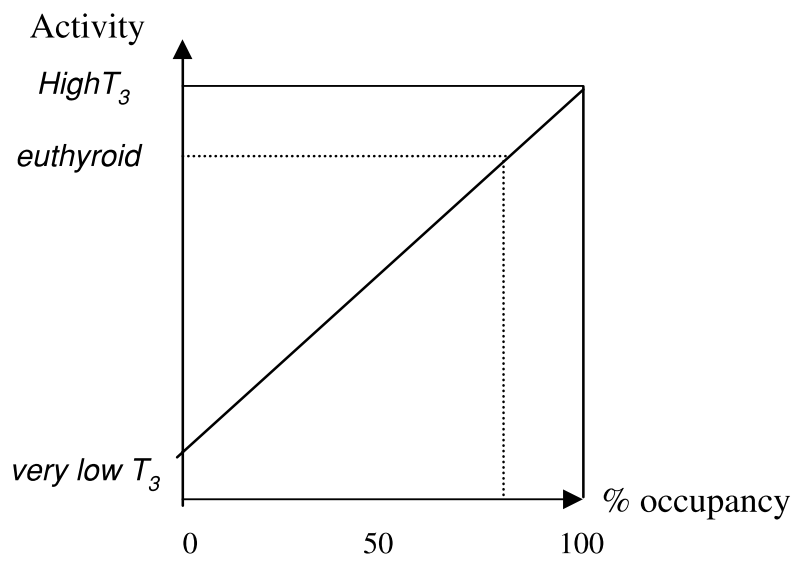

(b)

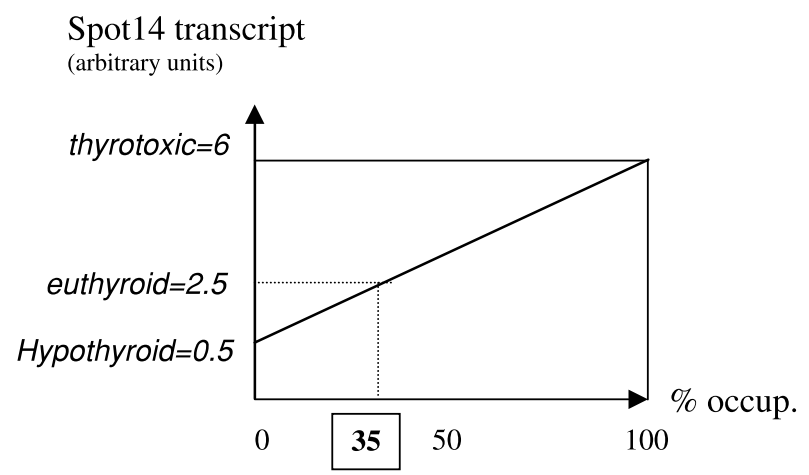

(d)

\section{DI activity}

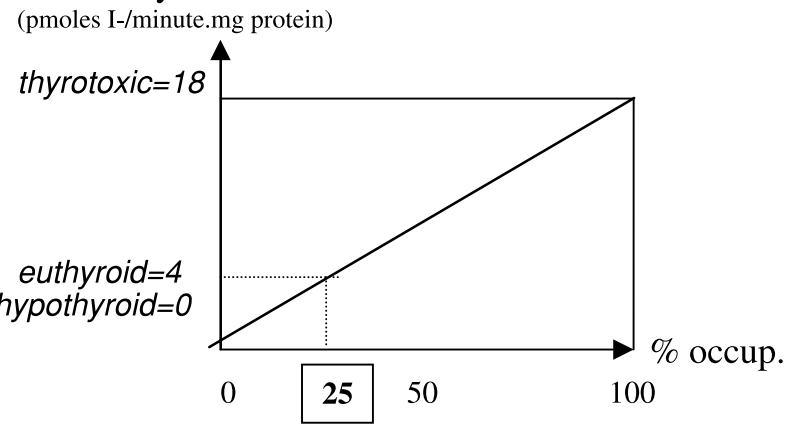

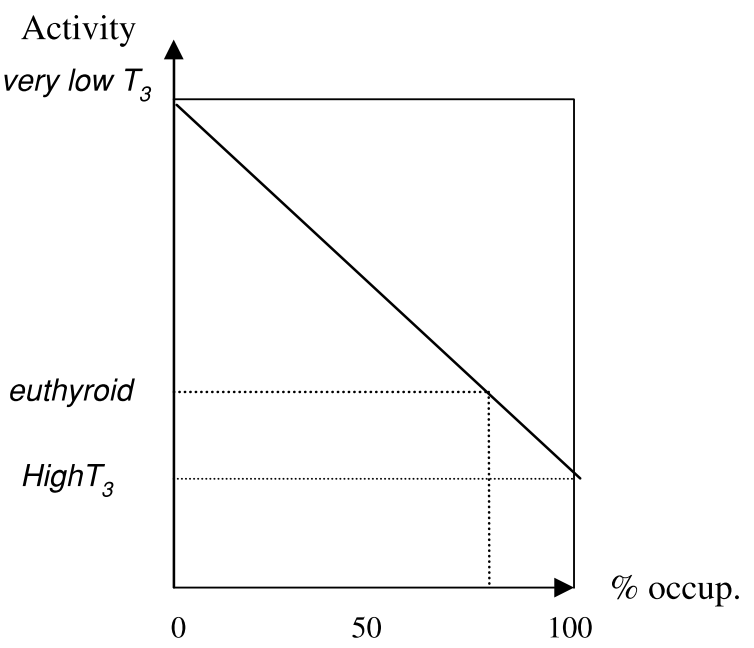

(c)

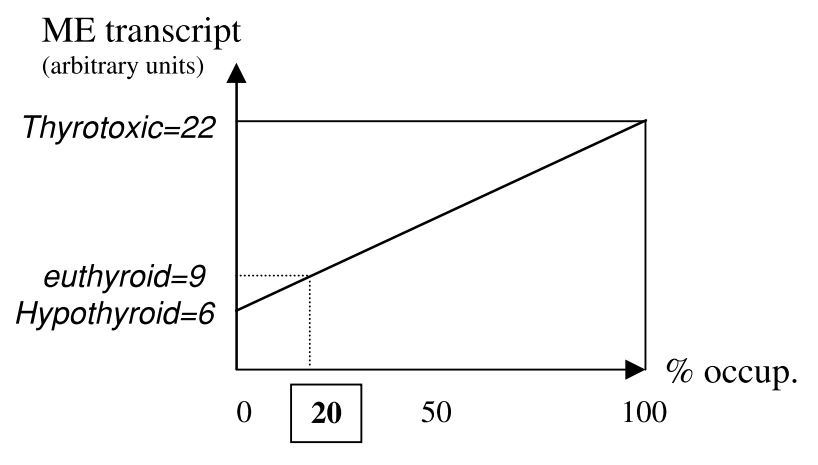

(e)

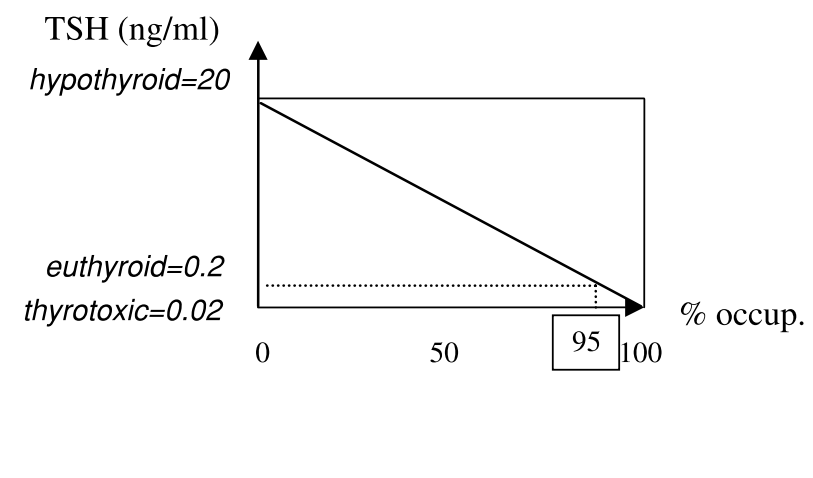


percentage of TR occupancy, it is possible to determine the percentage of ligand-bound TRs in tissues of euthyroid animals in vivo, provided the activity of a cell-specific, $\mathrm{T}_{3}$-regulated gene can be measured: (i) in hypothyroid animals (activity at $0 \%$ occupancy), (ii) in thyrotoxic animals (activity at $100 \%$ occupancy) and (iii) in euthyroid animals. A straight line can be drawn between the extreme values corresponding to $0 \%$ and $100 \%$ occupancy (Fig. 3a) and the percentage of holoTR in euthyroid animals is determined by extrapolation of the activity plotted onto the linear graph.

It is also possible to determine whether apoTRs are silent or whether they have an intrinsic activity, provided the gene activity can be measured in the absence of $\mathrm{TH}$ and in the absence of TR. If this activity is different in receptor-free and in TH-deprived mice, this means that unliganded TRs do have an activity in the corresponding tissue. The opportunity to measure the baseline activity of $\mathrm{T}_{3}$-target genes is provided by the availability of mice devoid of all TRs.

Although receptor occupancy can be determined from data obtained in different animal models, I will focus here on data from mice, because they give access to the baseline activity of some genes in the absence of TRs, through TR-knockout mice. It must be pointed out that this treatment of the data offers only an approximation of reality, for at least two reasons: (i) the determination of apoTR and holoTR activities assumes that the pharmacological treatment used to generate hypothyroid or thyrotoxic animals leads to $0 \%$ or $100 \%$ occupation of the TRs respectively, which is an approximation; (ii) the 'activity' parameters measured are steady-state amounts of transcripts, or serum concentrations of hormones, which do not represent exactly the transcriptional activity of TRs, as these amounts also depend on mRNA stability, translation, secretion, etc.
In liver, the expression of several genes $[M E$, Spot14 (Weiss et al. 1998), DI (Amma et al. 2001)] has been measured in hypothyroid, hyperthyroid and euthyroid mice. The amounts of each transcript measured in hypothyroid and thyrotoxic mice are plotted in Fig. 3b-d and straight lines have been drawn for each pair of data. The amount of each transcript measured in euthyroid mice has been plotted on the corresponding curve and the percentage of receptor occupancy has been determined on the abscissa (boxed numbers): extrapolated percentages are 35, 20 and 25\% for ME, Spot 14 and DI respectively (Fig. 3a, b and c respectively), suggesting that, in physiological conditions, TRs are mostly in the apoR configuration in hepatocytes. This conclusion is consistent with biochemical analyses that have shown that, in rat liver, the percentage of occupancy of TRs is around 45\% (Bianco et al. 2002). In another study, liver type I deiodinase activities were measured in hypothyroid and hyperthyroid wild-type and in TR $\alpha 1^{-/-} \mathrm{TR}^{-{ }^{-}-}$mice (Amma et al. 2001); the activity was found to be very similar in hypothyroid wild-type and in TR-free mice. Therefore, the basal transcription of the $D I$ gene in the absence of $\mathrm{TR}$ is not modified by the presence of apoTR in hypothyroid mice, indicating that apoTRs have no intrinsic activity in these cells or at least in the control of $D I$ promoter activity. As TR $\beta 1$ is the predominant isoform in this organ (Zhang et al. 2002), we can conclude that TR $\beta 1$ has no aporeceptor activity in liver. In conclusion, in liver, apoTRs are silent and TR activity in physiological conditions is low, as a result of a relatively low occupancy of the receptor. As a consequence, this organ has a high potential to respond to increased $\mathrm{T}_{3}$ concentrations, and hence is a potential therapeutic target for TR agonists.

In heart, TH stimulates the transcription of the $M H C a$ gene and represses the transcription of the

Figure 3 Determination of the fraction of occupied TRs. All graphs represent a $T_{3}$-dependent activity as a function of the percentage of occupancy of the TRs. On each graph, two values of this activity, one corresponding to very low TH concentrations (very low $\mathrm{T}_{3}$ or hypothyroid) and the other corresponding to saturating concentrations of $\mathrm{T}_{3}$ (high $\mathrm{T}_{3}$ or thyrotoxic), are plotted. The activity measured in euthyroid animals is plotted on the ordinate and the corresponding percentage of receptor occupancy is extrapolated on the abscissa (boxed numbers). (a) Theoretical graph representing the activity of a $\mathrm{T}_{3}$-activated (left) or $\mathrm{T}_{3}$-repressed (right) parameter as a function of receptor occupancy. (b) Amount of Spot14 transcript (arbitrary units) as a function of receptor occupancy. (With permission from Weiss et al. 1998.) (c) Amount of malic enzyme transcript (arbitrary units) as a function of receptor occupancy. (With permission from Weiss et al. 1998.) (d) Activity of type I deiodinase (pmol I- $/ \mathrm{mg}$ protein $\times \mathrm{min}$ ) as a function of receptor occupancy. (With permission from Amma et al. 2001.) (e) Serum concentration of TSH (ng/ml) as a function of receptor occupancy. (With permission from Weiss et al. 1997.) 
MHC $\beta$ gene, activates the transcription of the $\mathrm{K}^{+}$ ionic channel gene, $H C N 2$, and stimulates heart rate. The levels of expression of $M H C a$ and $M H C \beta$ genes in euthyroid mice have been found to be similar to those in thyrotoxic mice, suggesting that the percentage of holoTR in cardiomyocytes is close to $100 \%$ (Mansen et al. 2001). The knockout of the TRa gene leads to bradycardia (Johansson et al. 1999; Wilkstrom et al. 1998) and decreased expression of $\mathrm{K}^{+}$channels (Gloss et al. 2001), as the result of the depletion of holoTR. Mansen et al. (2001) have measured the expression of myosin heavy chain RNAs in wild-type hypothyroid and TR double-knockout mice, and found relative expression levels of 0.3 and 1 respectively for MHC $\alpha$ and 35 and 25 respectively for MHC $\beta$. As the levels of transcripts of MHC $\alpha$ and MHC $\beta$ are different in conditions of low $\mathrm{TH}$ and in the absence of TRs, this indicates that apoTRs have an intrinsic activity in heart, resulting in transcriptional activation of MHC $\beta$, and repression of $\mathrm{MHC} \alpha$.

In pituitary, TSHa and TSH $\beta$ genes are downregulated by $\mathrm{T}_{3}$. In response to $\mathrm{TH}$ deprivation, the concentration of TSH is increased severalfold; in contrast, the administration of high doses of $\mathrm{TH}$ produces a modest reduction in TSH (Fig. 3e) (Weiss et al. 1997). One can conclude that, in physiological conditions, most of the TRs ( 95\%) are liganded in thyrotrope cells. The production of $\mathrm{TSH}$ in $\mathrm{Pax} 8^{-}$mice, which have very low $\mathrm{TH}$ concentrations and are deeply hypothyroid, is twice that in TR double-knockout mice (Weiss et al. 2002a), suggesting that TRs exert aporeceptor activity in these cells. Remarkably, TR $\alpha 1$ but not $\operatorname{TR} \beta$ seems to be responsible for aporeceptormediated activation of TSH (Sadow et al. 2002).

\section{Fine-tuning of TR occupancy allows for physiological regulatory activity}

Receptor occupancy can be modified within a given tissue, by physiological variations in $\mathrm{T}_{3}$ concentrations, by pathological hypothyroidism or thyrotoxicosis, or by mutations within the receptors. One example of physiological variation of $T_{3}$ concentration is long-term adaptation to cold exposure. In response to $24 \mathrm{~h}$ exposure to cold in wild-type mice, serum $\mathrm{T}_{4}$ and $\mathrm{T}_{3}$ concentrations are unchanged; however, in brown adipose tissue, type II deiodinase activity is stimulated 10-20-fold, resulting in a local increase in $\mathrm{T}_{3}$ concentration that leads to increased heat production, thereby limiting the amplitude of hypothermia (de Jesus et al. 2001). When $\mathrm{DII}^{-/-}$mice are exposed to cold, the hypothermia is more severe because these mice cannot elicit $\mathrm{T}_{3}$-mediated heat production. In this situation, the availability of unoccupied TRs allows for adaptative responses to increases in $\mathrm{T}_{3}$ concentration elicited by external stimuli. ApoTRs are present in many tissues, where they participate in the mechanism of gene expression. The combination of holoTRs with active apoTRs permits a larger amplitude of transcriptional responses to moderate variations in $\mathrm{T}_{3}$ concentrations, as compared with silent apoTR. Physiological homeostasis depends on a precise balance between apoTRs and holoTRs, and excess $\mathrm{TH}$ leads to several metabolic and behavioural pathologies in adults (Braverman \& Utiger 2000).

\section{Conclusion and future directions in the investigation of apoTR function}

ApoTRs participate in the fine-tuning of $\mathrm{T}_{3}$-target genes. The saturation of TRs by high concentrations of $\mathrm{T}_{3}$ is not compatible with normal development and healthy adult life, suggesting that this tuning has an extreme importance. However, it is clear that apoTRs alone, as biochemical entities, do not have a fundamental physiological role. In other words, it is likely that, if one could substitute the natural apoTRs with silent receptors, which would bind DNA, but would not interfere with transcription, there would not be significant consequences for the physiology. To check this assumption properly, however, one would have to generate TRs devoid of their aporeceptor function. Considering that one of the best known functions of aporeceptors is their ability to recruit corepressors, an elegant approach to suppress aporeceptor activity would be to abrogate recruitment of corepressors by introducing point mutations into the $\mathrm{D}$ domain of the receptors by knock-in.

\section{References}

Amma LL, Campos-Barros A, Wang Z, Vennstrom B \& Forrest D 2001 Distinct tissue-specific roles for thyroid hormone receptors beta and alphal in regulation of type 1 deiodinase expression. Molecular Endocrinology 15 467-475. 
Arpin C, Pihlgren M, Fraichard A, Aubert D, Samarut J, Chassande O \& Marvel J 2000 Effects of T3R $\alpha 1$ and T3R $\alpha 2$ gene deletion on $\mathrm{T}$ and $\mathrm{B}$ lymphocyte development. Fournal of Immunology $\mathbf{1 6 4}$ $152-160$.

Becker N, Seugnet I, Guissouma H, Dupre SM \& Demeneix BA 2001 Nuclear corepressor and silencing mediator of retinoic and thyroid hormone receptors corepressor expression is incompatible with T(3)-dependent TRH regulation. Endocrinology 142 $5321-5331$

Bianco AC, Salvatore D, Gereben B, Berry MJ \& Larsen PR 2002 Biochemistry, cellular and molecular biology, and physiological roles of the iodothyronine selenodeiodinases. Endocrine Reviewes 23 38-89.

Bradley DJ, Towle HC \& Young WS III 1992 Spatial and temporal expression of alpha- and beta-thyroid hormone receptor mRNAs, including the beta 2-subtype, in the developing mammalian nervous system. Fournal of Neuroscience 12 2288-2302.

Braverman LE \& Utiger RD 2000 Introduction to thyrotoxicosis. In The Thyroid, edn 8, pp 515-517. Eds LE Braverman \& RD Utiger. Philadelphia: Lippincott Williams \& Wilkins.

Burrow GN, Fisher DA \& Larsen PR 1994 Maternal and fetal thyroid function. New England Fournal of Medicine 331 1072-1078.

Campos-Barros A, Amma LL, Faris JS, Shailam R, Kelley MW \& Forrest D 2000 Type 2 iodothyronine deiodinase expression in the cochlea before the onset of hearing. PNAS 97 1287-1292.

Chassande O, Fraichard A, Gauthier K, Flamant F, Legrand C, Savatier P, Laudet V \& Samarut J 1997 Identification of transcripts initiated from an internal promoter in the c-erbA alpha locus that encode inhibitors of retinoic acid receptor-alpha and triiodothyronine receptor activities. Molecular Endocrinology 11 $1278-1290$

Chassande O, Flamant F \& Samarut J 1999 Thyroid hormone receptor knockouts: their contribution to our understanding of thyroid hormone resistance. Current Opinion in Endocrinology and Diabetes 6 293-300.

Dace A, Zhao L, Park KS, Furuno T, Takamura N, Nakanishi M, West BL, Hanover JA \& Cheng S 2000 Hormone binding induces rapid proteasome-mediated degradation of thyroid hormone receptors. PNAS 97 8985-8990.

Damjanovski S, Sachs LM \& Shi YB 2002 Function of thyroid hormone receptors during amphibian development. Methods in Molecular Biology 202 153-176.

Feng X, Jiang Y, Meltzer P \& Yen PM 2000 Thyroid hormone regulation of hepatic genes in vivo detected by complementary DNA microarray. Molecular Endocrinology 14 947-955.

Feng X, Jiang Y, Meltzer P \& Yen PM 2001 Transgenic targeting of a dominant negative corepressor to liver blocks basal repression by thyroid hormone receptor and increases cell proliferation. Fournal of Biological Chemistry 276 15066-15072.

Flamant F \& Samarut J 1998 Involvement of thyroid hormone and its alpha receptor in avian neurulation. Developmental Biology 197 $1-11$.

Flamant F \& Samarut J 2003 Thyroid hormone receptors: lessons from knockout and knock-in mutant mice. Trends in Endocrinology and Metabolism 14 85-90.

Flamant F, Poguet AL, Plateroti M, Chassande O, Gauthier K, Streichenberger N, Mansouri A \& Samarut J 2002 Congenital hypothyroid Pax8(-/-) mutant mice can be rescued by inactivating the TRalpha gene. Molecular Endocrinology 16 24-32.

Forrest D, Sjoberg M \& Vennstrom B 1990 Contrasting developmental and tissue-specific expression of alpha and beta thyroid hormone receptor genes. EMBO fournal 9 1519-1528.

Fraichard A, Chassande O, Plateroti M, Roux J-P, Trouillas J, Dehay C, Gauthier K, Kedinger M, Malaval L, Rousset B \& Samarut J 1997 The T3R $\alpha$ gene encoding a thyroid hormone receptor is essential for post-natal development and thyroid hormone production. EMBO Fournal 16 4412-4420.
Gauthier K, Plateroti M, Harvey CB, Williams GR, Weiss RE, Refetoff S, Willot JF, Sundin V, Roux J-P, Malaval L, Hara M, Samarut J \& Chassande O 2001 Genetic analysis reveals different functions for the products of the TRalpha locus. Molecular Cell Biology 21 4748-4760.

Glass CK 1994 Differential recognition of target genes by nuclear receptor monomers, dimers, and heterodimers. Endocrine Reviews 15 391-340.

Glass CK \& Rosenfeld MG 2000 The coregulator exchange in transcriptional functions of nuclear receptors. Genes and Development 200014 121-141.

Glinoer D 2000 Thyroid disease during pregnancy. In The Thyroid, edn 8, pp 1013-1027. Eds LE Braverman \& RD Utiger. Philadelphia: Lippincott Williams \& Wilkins.

Gloss B, Trost SU, Blum WF, Swanson EA, Clark R, Winkfein R, Janzen KM, Giles W, Chassande O, Samarut J \& Dillman WH 2001 Cardiac ion channel expression and contractile function in mice with deletion of thyroid hormone receptor $\alpha$ or $\beta$. Endocrinology 142 544-550.

Hadj-Sahraoui N, Seugnet I, Ghorbel MT \& Demeneix B 2000 Hypothyroidism prolongs mitotic activity in the post-natal mouse brain. Neuroscience Letters 280 79-82.

Hashimoto K, Curty FH, Borges PP, Lee CE, Abel ED, Elmquist JK, Cohen RN \& Wondisford FE 2001 An unliganded thyroid hormone receptor causes severe neurological dysfunction. PNAS 98 3998-4003.

Hu X \& Lazar MA 2000 Transcriptional repression by nuclear hormone receptors. Trends in Endocrinology and Metabolism 11 6-10.

Jepsen K, Hermanson O, Onami TM, Gleiberman AS, Lunyak V, McEvilly RJ, Kurokawa R, Kumar V, Liu F, Seto E, Hedrick SM, Mandel G, Glass CK, Rose DW \& Rosenfeld MG 2000 Combinatorial roles of the nuclear receptor corepressor in transcription and development. Cell 102 753-763.

de Jesus LA, Carvalho SD, Ribeiro MO, Schneider M, Kim SW, Harney JW, Larsen PR \& Bianco AC 2001 The type 2 iodothyronine deiodinase is essential for adaptive thermogenesis in brown adipose tissue. Fournal of Clinical Investigation 108 1379-1385.

Johansson C, Gothe S, Forrest D, Vennstrom B \& Thoren P 1999 Cardiovascular phenotype and temperature control in mice lacking thyroid hormone receptor-beta or both alphal and beta. American Fournal of Physiology 276 H2006-H2012.

Kamiya Y, Puzianowska-Kuznicka M, McPhie P, Nauman J, Cheng SY \& Nauman A 2002 Expression of mutant thyroid hormone nuclear receptors is associated with human renal clear cell carcinoma. Carcinogenesis 23 25-33.

Kaneshige M, Kaneshige K, Zhu X, Dace A, Garrett L, Carter TA, Kazlauskaite R, Pankratz DG, Wynshaw-Boris A, Refetoff S, Weintraub B, Willingham MC, Barlow G \& Cheng S 2000 Mice with a targeted mutation in the thyroid hormone beta receptor gene exhibit impaired growth and resistance to thyroid hormone. PNAS 97 13209-13214.

Kaneshige M, Suzuki H, Kaneshige K, Cheng J, Wimbrow H, Barlow C, Willingham MC \& Cheng S 2001 A targeted dominant negative mutation of the thyroid hormone alpha 1 receptor causes increased mortality, infertility, and dwarfism in mice. PNAS 98 15095-15100.

Koibuchi N \& Chin WW 2000 Thyroid hormone action and brain development. Trends in Endocrinology and Metabolism 11 123-128.

Lin KH, Shieh HY, Chen SL \& Hsu HC 1999 Expression of mutant thyroid hormone nuclear receptors in human hepatocellular carcinoma cells. Molecular Carcinogens 26 53-61.

Liu Y, Takeshita A, Misiti S, Chin WW \& Yen PM 1998 Lack of coactivator interaction can be a mechanism for dominant negative activity by mutant thyroid hormone receptors. Endocrinology $\mathbf{1 3 9}$ 197-204.

McCabe CJ, Gittoes NJ, Sheppard MC \& Franklyn JA 1999 Thyroid receptor alphal and alpha2 mutations in nonfunctioning 
pituitary tumours. Fournal of Clinical Endocrinology and Metabolism $\mathbf{8 4}$ 649-653.

Mansen A, Yu F, Forrest D, Larsson L \& Vennstrom B 2001 TRs have common and isoform-specific functions in regulation of the cardiac myosin heavy chain genes. Molecular Endocrinology $\mathbf{1 5}$ 2106-2114.

Mansouri A, Chowdhury K \& Gruss P 1998 Follicular cells of the thyroid gland require Pax8 gene function. Nature Genetics 19 87-90.

Morte B, Manzano J, Scanlan T, Vennstrom B \& Bernal J 2002 Deletion of the thyroid hormone receptor alpha 1 prevents the structural alterations of the cerebellum induced by hypothyroidism. PNAS 99 3985-3989.

Puzianowska-Kuznicka M, Krystyniak A, Madej A, Cheng SY \& Nauman J 2002 Functionally impaired TR mutants are present in thyroid papillary cancer. Fournal of Clinical Endocrinology and Metabolism 87 1120-1128.

Refetoff S 2000 Resistance to thyroid hormone. In The Thyroid edn 8, pp 1028-1043. Eds LE Braverman \& RD Utiger. Philadelphia: Lippincott Williams \& Wilkins.

Rüsch A, Ng L, Goodyear R, Oliver D, Lisoukov I, Vennström B, Richardson G, Kelley MW \& Forest D 2001 Retardation of cochlear maturation and impaired hair cell function caused by deletion of all known thyroid hormone receptors. Fournal of Neuroscience 21 9792-9800.

Sachs LM, Damjanovski S, Jones PL, Li Q, Amano T, Ueda S, Shi YB \& Ishizuya-Oka A 2000 Dual functions of thyroid hormone receptors during Xenopus development. Comparative Biochemistry and Physiology. Part B, Biochemistry and Molecular Biology 126 199-211.

Sachs LM, Jones PL, Havis E, Rouse N, Demeneix BA \& Shi YB 2002 Nuclear receptor corepressor recruitment by unliganded thyroid hormone receptor in gene repression during Xenopus laevis development. Molecular Cell Biology 22 8527-8538.

Sadow PM, Chassande O, Gauthier K, Samarut J, Xu J, O’Malley BW \& Weiss RE 2003 Specificity of thyroid hormone receptor subtype and steroid receptor coactivator (SRC)-1 on thyroid hormone action. American fournal of Physiology, Endocrinology and Metabolism 284 36-46.

Safer JD, Cohen RN, Hollenberg AN \& Wondisford FE 1998 Defective release of corepressor by hinge mutants of the thyroid hormone receptor found in patients with resistance to thyroid hormone. Journal of Biological Chemistry 273 30175-30182.

Sjoberg M, Vennstrom B \& Forrest D 1992 Thyroid hormone receptors in chick retinal development: differential expression of mRNAs for alpha and N-terminal variant beta receptors. Development 114 39-47.

Strait KA, Schwartz HL, Perez-Castillo A \& Oppenheimer JH 1990 Relationship of c-erbA mRNA content to tissue triiodothyronine nuclear binding capacity and function in developing and adult rats. Fournal of Biological Chemistry 265 10514-10521.
Tagami T, Gu WX, Peairs PT, West BL \& Jameson JL 1998 A novel natural mutation in the thyroid hormone receptor defines a dual functional domain that exchanges nuclear receptor corepressors and coactivators. Molecular Endocrinology 12 1888-1902.

Tinnikov A, Nordstrom K, Thoren P, Kindblom JM, Malin S, Rozell B, Adams M, Rajanayagam O, Pettersson S, Ohlsson C, Chatterjee K \& Vennstrom B 2002 Retardation of post-natal development caused by a negatively acting thyroid hormone receptor alphal. EMBO Journal 21 5079-5087.

Weiss RE, Forrest D, Pohlenz J, Cua K, Curran T \& Refetoff S 1997 Thyrotropin regulation by thyroid hormone in thyroid hormone receptor beta-deficient mice. Endocrinology 138 3624-3629.

Weiss RE, Murata Y, Gua K, Hayashi Y, Seo H \& Refetoff S 1998 Thyroid hormone action on liver, heart, and energy expenditure in thyroid hormone receptor beta-deficient mice. Endocrinology 139 4945-4952.

Weiss RE, Xu J, Ning G, Pohlenz J, O'Malley BW \& Refetoff S 1999 Mice deficient in the steroid receptor co-activator 1 (SRC-1) are resistant to thyroid hormone. EMBO Fournal 18 1900-1904.

Weiss RE, Chassande O, Koo EK, Macchia PE, Cua K, Samarut J \& Refetoff S 2002a Thyroid function and effect of aging in combined hetero/homozygous mice deficient in thyroid hormone receptors alpha and beta genes. Fournal of Endocrinology 172 177-185.

Weiss RE, Gehin M, Xu J, Sadow PM, O'Malley BW, Chambon P \& Refetoff S $2002 b$ Thyroid function in mice with compound heterozygous and homozygous disruptions of SRC-1 and TIF-2 coactivators: evidence for haploinsufficiency. Endocrinology 143 $1554-1557$.

Wilkstrom L, Johansson C, Salto C, Barlow C, Campos Barros A, Baas F, Forrest D, Thoren P \& Vennstrom B 1998 Abnormal heart rate and body temperature in mice lacking thyroid hormone receptor alpha 1. EMBO fournal 17 455-461.

Williams GR 2000 Cloning and characterization of two novel thyroid hormone receptor beta isoforms. Molecular Cell Biology 20 8329-8342.

Yen PM 2001 Physiological and molecular basis of thyroid hormone action. Physiology Reviews 81 1097-1142.

Zhang XY, Kaneshige M, Kamiya Y, Kaneshige K, McPhie P \& Cheng SY 2002 Differential expression of thyroid hormone receptor isoforms dictates the dominant negative activity of mutant beta receptor. Molecular Endocrinology 16 2077-2092.

Received 20 January 2003 Accepted 8 May 2003 